\title{
Frequent attenders at primary care out-of-hours services: a registry-based observational study in Norway
}

\author{
Hogne Sandvik ${ }^{1 *}$ (D) and Steinar Hunskaar ${ }^{1,2}$
}

\begin{abstract}
Background: Out-of-hours $(\mathrm{OOH})$ services are often consulted for problems that are non-urgent. Some of these patients are frequent attenders (FAs) who may constitute a heavy burden on the $\mathrm{OOH}$ service. The aim of the present study was to analyse FAs in a comprehensive material, covering all patients who have visited $\mathrm{OOH}$ services in Norway during a 10-year period.
\end{abstract}

Methods: FA was defined as a patient having $\geq 5$ consultations during one year. A cohort of all 15,172 FAs in 2008 was followed until 2017, with a description of demographics, consultations, and diagnoses for each year. FAs in 2017 were also analysed with more extreme definitions ( $\geq 10, \geq 20, \geq 30$ consultations). To analyse predictors for FA a logistic regression analysis was performed on the 2017 data.

Results: FAs constituted $2 \%$ of all patients (U-shaped age curve and female overrepresentation) and approximately $10 \%$ of all consultations each year. 59.8\% of the cohort was never FA again, $17.7 \%$ had one relapse, $8.6 \%$ two, and 4.4\% had three relapses. 22.8\% was also a FA in 2009. Thereafter the percentage gradually declined to $6.2 \%$ in 2017. Only $0.8 \%$ of the original cohort were persistent FAs throughout the 10-year period. FAs were three times as likely to be given a psychological diagnosis as the average $\mathrm{OOH}$ patient, and this percentage increased in persistent and more extreme FAs. FAs tended to seek help at inconvenient hours (late evening and night), and increasingly so the more extreme they were. Also, they needed more consultation time and more often received home visits. The logistic regression analysis identified the following predictors for becoming FA (odds ratio =OR): Female (OR 1.17), age $0-1$ years (OR 3.46), age 70+ (OR 1.57), small municipality (OR 1.61), psychological diagnosis (OR 10.00), social diagnosis (OR 5.97), cancer (OR 6.76), diabetes (OR 4.65), and chronic obstructive pulmonary disease (OR 7.81).

Conclusions: FAs were most common among the youngest children and among the elderly, increasing with age. Females were overrepresented, as were patients with psychosocial problems and various chronic somatic conditions. The majority were only temporary FAs.

Keywords: Norway, Out-of-hours medical care, Emergency care, Primary health care

\section{Background}

It is not uncommon for patients to seek help out of hours $(\mathrm{OOH})$ for problems that are non-urgent, putting unnecessary strain on the $\mathrm{OOH}$ service $[1,2]$. A non-urgent consultation may be defined as a consultation that could have waited until office hours the next day $[1,2]$. Special attention has been given to so called frequent attenders

\footnotetext{
* Correspondence: hogne.sandvik@uib.no

${ }^{1}$ National Centre for Emergency Primary Health Care, Uni Research Health,

Kalfarveien 31, 5018 Bergen, Norway

Full list of author information is available at the end of the article
}

(FAs) [1, 3-6]. Patients with medically unnecessary contacts are more often FAs [1]. Many studies on FAs have been performed in general practice and hospital emergency departments [7-18]. There is a strong association between frequent attendance $\mathrm{OOH}$ and frequent attendance during daytime general practice [8].

Different definitions have been used to identify FAs, making it difficult to compare the findings. In a review paper of FAs in general practice (published in 2005) Vedsted \& Christensen identified 54 studies where the proportion of FA (with heterogeneous definitions) 
ranged from 3 to $25 \%$ of patients, or $2-24$ contacts during varying time intervals [7]. Some included telephone contacts, others did not. When the top decile of the attenders was used as a definition of FA, it encompassed $30-50 \%$ of all contacts.

Studies of FAs in $\mathrm{OOH}$ services have also used different definitions. In a Danish study in 1990 the top decile was used as definition of FA, encompassing $42 \%$ of all contacts [3]. Another Danish study in 1997-98 included patients with $\geq 5$ contacts during one year [5]. In a Dutch study in 2007 two definitions were used, patients with 3-6 contacts during a year were labelled FA (9\% of attenders), those with $\geq 7$ contacts VFA (very frequent attender, $1 \%$ of attenders) [4]. In another Dutch study in 2009-12 FA was defined as patients with $\geq 3$ contacts during one year [1]. In 2011 an Italian study defined FA as patients with $\geq 3$ contacts (including telephone contacts) during one year [6].

A majority of FAs in general practice and $\mathrm{OOH}$ tends to be female and elderly $[1,7,14]$, while there is a male dominance among FAs in hospital emergency departments $[12,15,16,18]$. Only rarely have children been included in studies [6]. Usually, FAs are characterized by psychological disorders $[4,6,10-13,19-21]$ and social disorders $[10,22,23]$, but also chronic somatic disease has been reported as more common among FAs [10, 11, 20].

In follow-up studies a typical finding is that most frequent attendance is temporary $[3,4,9-11,17,18]$. A medical problem may develop over time and require several contacts. This is normal and should not be labelled inappropriate or unnecessary. However, it may be considered inappropriate use of $\mathrm{OOH}$ services. Persistent FAs are often characterized by psychological, social and addictive disorders, and chronic somatic disease [10, 11, 17, 18, 24].

Most studies of FAs are limited to single or a few locations, selected age groups, and short time periods. Few of them are from $\mathrm{OOH}$ services. It is likely that many FAs would be better taken care of by their regular general practitioner, rather than a random $\mathrm{OOH}$ doctor. Even being few, the FAs exert a heavy work load on the $\mathrm{OOH}$ services, and many have problems that are not well suited for a one-encounter-only service like the $\mathrm{OOH}$. Detailed knowledge about FAs may thus help us to develop better services, both for patients and providers, and identify factors that may be target for intervention.

The aim of the present study was therefore to analyse frequent attenders, very frequent or extreme attenders, and persistent frequent attenders in a comprehensive material, covering all patients who have visited $\mathrm{OOH}$ services in Norway during a 10-year period.

\section{Organization of Norwegian health care}

In Norway the state is responsible for hospitals, while the primary health care system is the responsibility of more than 400 municipalities. Primary care physicians (regular general practitioners, RGPs) are organized in a list system, to which more than $99 \%$ of the inhabitants subscribe. On average, each RGP cares for approximately 1100 inhabitants. RGPs are gate keepers, patients cannot decide by themselves to go to a hospital or emergency department.

$\mathrm{OOH}$ services are also the responsibility of municipalities. Some municipalities have their own $\mathrm{OOH}$ service, others cooperate. In 2016 there were 182 different $\mathrm{OOH}$ services in Norway, 81 municipal and 101 intermunicipal cooperatives [25]. OOH services are mainly staffed by RGPs, but other physicians may also participate.

$\mathrm{OOH}$ services are based on fee for service. As for out of pocket expenses, children younger than 16 years pay nothing. Others pay a little more than 30 USD for a consultation at the clinic and 40 USD for a home visit. FAs will often pay nothing since there is a limit (approximately 275 USD) to how much an individual have to pay for health services during one calendar year. In addition, the doctor or the $\mathrm{OOH}$ service sends an electronic compensation claim to the Norwegian Health Economics Administration (HELFO). Thus, HELFO has complete records of all patient contacts with $\mathrm{OOH}$ services in Norway. Compensation claims are time stamped and include a diagnosis according to ICPC-2 (International Classification of Primary Care, 2nd edition) [26]. There are different fee codes for different types of contact and for numerous different procedures. A time fee is claimed when the consultation lasts more than $20 \mathrm{~min}$.

\section{Methods}

The National Centre for Emergency Primary Health Care publishes annual statistics based on $\mathrm{OOH}$-data provided by HELFO [27]. These data are anonymized, but since 2008 HELFO has included a pseudo-id based on the patient's ID-number. This enables us to follow individuals' use of $\mathrm{OOH}$ services through consecutive years. Due to privacy, the name of the individual municipality is not included in the material, but the municipalities are categorized into five groups based on the number of inhabitants.

All Norwegian citizens are given a unique personal identification number (ID-number) at birth. This number is used in various official records, including HELFO. Foreigners moving to Norway to stay for more than six months are also given an ID-number. As a rule all medical services will register a patient's ID-number. However, in emergency settings these numbers are not always available.

The present study was based on data used for the annual statistics, but we included only face-to-face consultations with a doctor at the $\mathrm{OOH}$ clinic or during a home visit. Pseudo-id was lacking in $22.2 \%$ of all consultations in 2008, gradually improving until 2017, when only $1.8 \%$ of the consultations were without pseudo-id. 
The diagnostic distribution among consultations with or without pseudo-id varied slightly (data not shown).

The number of consultations remained stable throughout the period. There were 1,402,452 consultations in 2008 and in 2017 there were 1,399,001. The highest number was recorded in 2012 (1,436,297 consultations). As we have only included consultations with a pseudo-id, our material includes more consultations in 2017 (1,373,987 consultations) than in $2008(1,091,483$ consultations). The population of Norway was approximately 4.75 million in 2008 and 5.25 million in 2017.

We defined a frequent attender (FA) as a patient with five or more $\mathrm{OOH}$ consultations during one calendar year. By this definition, FAs made up $2 \%$ of all patients all years 2008-2017, accounting for approximately $10 \%$ of all consultations.

We established a cohort of all FAs found in 2008 and followed them until 2017. We recorded how many of the cohort patients were still frequent attenders in each year, and the number of consultations all cohort patients had in each year. Patients' gender and age group were also recorded, in addition to the diagnostic distribution according to ICPC-2 chapters. A similar, separate analysis of psychological diagnoses among cohort patients was also performed.

The material from 2017 was subjected to a more detailed analysis. We used different definitions of frequent attenders ( $\geq 5, \geq 10, \geq 20, \geq 30$ consultations) and recorded diagnostic distribution, number of patients, consultations, gender, age, percentage of home visits, percentage of long consultations (> $20 \mathrm{~min}$ ), and distribution of contacts during day, night, and week.

A logistic regression analysis was performed with being a FA ( $\geq 5$ consultations) in 2017 or not as the dependent variable. Explanatory variables were gender, age group, number of inhabitants in the municipality (five groups), and five different diagnostic groups:

1. Psychological (ICPC-2 chapter P)
2. Social (ICPC-2 chapter Z)

3. Diabetes (ICPC-2 codes T89, T90)

4. Chronic obstructive pulmonary disease (COPD) (ICPC-2 code R95)

5. Cancer (ICPC-2 codes A79, B72, B73, B74, D74, D75, D76, D77, F74, H75, K72, L71, N74, R84, R85, S77, T71, T72, T73, U75, U76, U77, W72, X75, X76, $\mathrm{X} 77, \mathrm{Y} 77, \mathrm{Y} 78$ )

The two chronic somatic diagnoses (diabetes and COPD) were chosen because they are prevalent and may cause complications or exacerbations. Individual patients were labelled with these diagnoses if they had at least one $\mathrm{OOH}$ contact with the relevant ICPC-2 code in 2017.

Since the material encompasses all reimbursement claims and not a sample, the differences identified are real and not fraught with statistical uncertainty. The data are therefore presented without confidence intervals and no statistical tests have been undertaken, except for the logistic regression analysis.

\section{Results}

\section{The 2008 cohort}

In 2008 there were 1,091,483 consultations with 746,241 patients identified by pseudo-id (1.5 consultations per patient). Of these, 15,172 patients were identified as FAs and included in the cohort (Table 1). The majority (59.8\%) of the cohort patients were never FA again during the following 10 -year period.

In $200922.8 \%$ of the patients in the 2008 cohort were still FAs. During the next years the percentage of FAs in the 2008 cohort gradually declined to $6.2 \%$ in 2017 . Likewise, the average number of consultations per patient in the cohort declined from 7.0 to 3.2, still more than twice the average number of consultations among all $\mathrm{OOH}$ patients. The percentage of cohort patients who remained persistent FAs every year since 2008, declined from $22.8 \%$ in 2009 to $0.8 \%$ in 2017 (Table 1).

Table 1 Characteristics of all identified $\mathrm{OOH}$ patients in 2008 and a cohort of frequent attenders established in 2008

\begin{tabular}{|c|c|c|c|c|c|c|c|c|c|c|c|}
\hline & \multirow[b]{2}{*}{ All 2008} & \multicolumn{10}{|c|}{ Cohort of frequent attenders in 2008 ( $n=15,172$ patients) } \\
\hline & & 2008 & 2009 & 2010 & 2011 & 2012 & 2013 & 2014 & 2015 & 2016 & 2017 \\
\hline Number of patients who have consulted at least once during the year & 746,241 & 15,172 & 11,508 & 9690 & 8745 & 7859 & 7197 & 6614 & 6196 & 5772 & 5421 \\
\hline Percentage frequent attenders of cohort each year & 2.0 & 100.0 & 22.8 & 16.3 & 13.3 & 11.0 & 9.6 & 8.5 & 7.8 & 6.7 & 6.2 \\
\hline Percentage frequent attenders of cohort every year since 2008 & 2.0 & 100.0 & 22.8 & 9.9 & 5.5 & 3.7 & 2.4 & 1.8 & 1.3 & 1.0 & 0.8 \\
\hline Consultations per patient & 1.5 & 7.0 & 4.4 & 4.0 & 3.8 & 3.6 & 3.5 & 3.5 & 3.4 & 3.3 & 3.2 \\
\hline Percentage females & 52.5 & 55.7 & 56.8 & 58.1 & 58.8 & 60.3 & 60.6 & 61.1 & 61.3 & 62.0 & 61.6 \\
\hline Percentage aged 0-1 in 2008 & 4.4 & 10.3 & 11.0 & 10.8 & 10.4 & 9.6 & 9.1 & 8.9 & 8.9 & 8.6 & 8.4 \\
\hline Percentage aged 2-15 in 2008 & 16.0 & 10.0 & 9.8 & 9.5 & 9.6 & 9.5 & 9.2 & 9.3 & 9.5 & 10.1 & 9.8 \\
\hline Percentage aged 16-69 in 2008 & 66.5 & 59.9 & 61.9 & 65.1 & 67.0 & 69.5 & 71.6 & 72.8 & 73.7 & 74.3 & 76.0 \\
\hline Percentage aged 70+ in 2008 & 13.1 & 19.9 & 17.3 & 14.6 & 13.0 & 11.5 & 10.1 & 9.0 & 7.9 & 7.0 & 5.8 \\
\hline
\end{tabular}


Table 1 also demonstrates that females were overrepresented among FAs, and even more so among cohort patients who continued to visit the $\mathrm{OOH}$ services during the following years. The age distribution in the cohort changed over the years. Those who were $\geq 70$ years old in 2008 gradually decreased, while the age group 1569 years increased. Only a small decrease was observed among those who were $0-1$ years in 2008 .

There were 124 patients who remained persistent FAs every year during the 10-year period. Two thirds of them were women, mean age was 41.2 years in 2008 , median 39.5, and range 16-84. In $200822.2 \%$ of their consultations were for psychological and $1.2 \%$ for social diagnoses. In 2017 the corresponding numbers were 24.5\% psychological and $2.0 \%$ social diagnoses.

Of the 15,172 cohort patients $17.7 \%$ had one relapse as FA, $8.6 \%$ had two, and $4.4 \%$ had three relapses during the following 10-year period. Table 2 demonstrates that the cohort patients had an increased risk of being FA until 2012, after which the risk was less than $2 \%$. The table also shows that there was an increased risk of being FA again the first years after a relapse, especially if the relapse took place during the first years.

In 2008 FAs were three times as likely to be given a psychological diagnosis as the average $\mathrm{OOH}$ patient. During the years after 2008 cohort patients were even more prone to receive a P-diagnosis. Social problems (Z-diagnoses) were also more prevalent among FAs (Table 3).

Table 4 shows the distribution of the most common psychological diagnoses among all patients and among FAs in 2008, and among the 2008 cohort patient in all years from 2008 to 2017. Chronic alcohol abuse, drug abuse, schizophrenia, and personality disorders were more common among FAs, and even more so among cohort patients in the following years.

\section{The 2017 data}

The percentage of FAs was high among the youngest children, but declined rapidly, reaching a low at age 10-12 years. Thereafter the percentage increased and stabilized around $2 \%$ until increasing again among the elderly (Fig. 1).

Increasing the threshold for defining FAs resulted in progressively more deviant patients' characteristics. FAs were more prone to contact the $\mathrm{OOH}$ services during night and late evening, and more so when the FA definition was sharpened (Fig. 2). An opposite tendency was found for consulting during weekends (Table 5). With sharpened FA definition an increasing percentage of the patients were female, more home visits were performed, and the physicians claimed more time fees for long consultations. Table 5 also demonstrates that the percentage of psychological and social diagnoses increased considerably when the FA definition was sharpened.

The logistic regression analysis showed that females were more likely to be FAs, as were children aged 01 years and the elderly. FAs were also more common in small municipalities. Both psychological, social and cancer diagnoses were strong predictors of becoming a FA, as were diabetes and COPD (Table 6).

\section{Discussion}

We found that frequent attenders (FAs) were most prevalent among the youngest children and among the elderly, increasing with age. Females were overrepresented, as were patients with psychosocial problems and various chronic somatic conditions.

Most were only temporary FAs, almost $60 \%$ were never FA again during the 10-year period. Only $22.8 \%$ were also FA the next year (2009). After four years without relapse the risk for being a FA was at the same level as for the average $\mathrm{OOH}$ patient. This is in line with

Table 2 Overview of patients in the original 2008 cohort of 15,172 frequent attenders (FAs) who had their first relapse as FA the following years. For each year the table shows the percentage who were never FA again after their first relapse and the percentage who were FA the following years

\begin{tabular}{|c|c|c|c|c|c|c|c|c|c|c|c|}
\hline & \multirow[b]{2}{*}{$\mathrm{N}$} & \multirow[b]{2}{*}{$\begin{array}{l}\text { Percentage of the original } \\
\text { cohort }(n=15,172)\end{array}$} & \multirow[b]{2}{*}{$\begin{array}{l}\text { Never FA } \\
\text { again (\%) }\end{array}$} & \multicolumn{8}{|c|}{ Percentage FA each year after first relapse as FA } \\
\hline & & & & 2010 & 2011 & 2012 & 2013 & 2014 & 2015 & 2016 & 2017 \\
\hline First relapse as FA in 2009 & 3454 & 22.8 & 36.0 & 43.4 & 33.2 & 27.6 & 23.8 & 21.0 & 18.4 & 16.6 & 14.4 \\
\hline First relapse as FA in 2010 & 967 & 6.4 & 46.4 & & 33.3 & 24.0 & 19.5 & 15.9 & 16.4 & 12.5 & 12.7 \\
\hline First relapse as FA in 2011 & 550 & 3.6 & 49.3 & & & 29.5 & 21.8 & 15.6 & 15.8 & 10.2 & 11.1 \\
\hline First relapse as FA in 2012 & 327 & 2.2 & 54.4 & & & & 23.9 & 19.3 & 19.6 & 14.7 & 11.9 \\
\hline First relapse as FA in 2013 & 247 & 1.6 & 54.7 & & & & & 27.5 & 18.6 & 11.3 & 14.6 \\
\hline First relapse as FA in 2014 & 190 & 1.3 & 57.4 & & & & & & 28.4 & 18.9 & 18.9 \\
\hline First relapse as FA in 2015 & 145 & 1.0 & 75.9 & & & & & & & 17.9 & 11.0 \\
\hline First relapse as FA in 2016 & 128 & 0.8 & 71.1 & & & & & & & & 28.9 \\
\hline First relapse as FA in 2017 & 94 & 0.6 & - & & & & & & & & \\
\hline
\end{tabular}


Table 3 Diagnostic distribution (percentage of consultations) in 2008 and in a cohort of frequent attenders in 2008 in subsequent years

\begin{tabular}{|c|c|c|c|c|c|c|c|c|c|c|c|}
\hline \multirow[b]{2}{*}{ ICPC-2 chapter } & \multirow[b]{2}{*}{ All 2008} & \multicolumn{10}{|c|}{ Cohort of frequent attenders in 2008 ( $n=15,172$ patients) } \\
\hline & & 2008 & 2009 & 2010 & 2011 & 2012 & 2013 & 2014 & 2015 & 2016 & 2017 \\
\hline A: General. unspecified & 10.3 & 11.5 & 12.2 & 11.1 & 12.1 & 12.5 & 13.2 & 13.5 & 14.1 & 13.4 & 13.4 \\
\hline B: Blood etc. & 0.3 & 0.4 & 0.3 & 0.3 & 0.3 & 0.3 & 0.3 & 0.2 & 0.3 & 0.3 & 0.3 \\
\hline D: Digestive & 10.1 & 11.5 & 11.8 & 12.2 & 12.1 & 11.1 & 11.8 & 12.8 & 11.5 & 11.7 & 12.2 \\
\hline F: Eye & 4.7 & 2.1 & 1.9 & 1.9 & 1.9 & 1.9 & 1.7 & 1.9 & 1.9 & 1.9 & 1.9 \\
\hline $\mathrm{H}$ : Ear & 3.2 & 2.4 & 1.9 & 1.7 & 1.9 & 1.6 & 1.5 & 1.3 & 1.3 & 1.3 & 1.2 \\
\hline K: Cardiovascular & 4.1 & 5.0 & 4.2 & 4.2 & 4.3 & 3.8 & 3.9 & 3.7 & 3.8 & 4.2 & 4.2 \\
\hline L: Musculoskeletal & 16.3 & 11.3 & 11.8 & 12.8 & 13.4 & 13.3 & 13.6 & 13.2 & 14.3 & 14.9 & 14.2 \\
\hline N: Neurological & 3.7 & 4.6 & 4.7 & 4.7 & 4.8 & 4.8 & 5.0 & 4.8 & 4.9 & 5.0 & 5.2 \\
\hline P: Psychological & 4.3 & 12.9 & 15.6 & 16.9 & 16.1 & 17.3 & 18.3 & 17.5 & 17.4 & 16.8 & 16.4 \\
\hline R: Respiratory & 22.2 & 20.9 & 20.0 & 18.1 & 16.9 & 17.3 & 15.1 & 14.4 & 14.0 & 14.7 & 14.8 \\
\hline S: Skin & 11.2 & 6.3 & 5.8 & 6.3 & 6.2 & 5.9 & 6.0 & 6.4 & 7.0 & 6.7 & 6.9 \\
\hline T: Endocrine etc. & 0.8 & 0.9 & 0.9 & 0.8 & 1.0 & 0.8 & 0.8 & 0.9 & 1.0 & 1.0 & 0.9 \\
\hline U: Urological & 5.8 & 6.7 & 6.1 & 6.0 & 5.9 & 5.9 & 5.7 & 6.2 & 5.6 & 5.3 & 5.7 \\
\hline W: Pregnancy etc & 1.3 & 1.2 & 0.9 & 0.9 & 0.9 & 0.8 & 0.9 & 0.7 & 0.9 & 0.6 & 0.6 \\
\hline X: Female genital & 0.9 & 0.9 & 0.9 & 1.0 & 0.9 & 1.1 & 0.9 & 1.0 & 0.8 & 0.8 & 0.8 \\
\hline Y: Male genital & 0.7 & 0.6 & 0.7 & 0.6 & 0.8 & 0.8 & 0.6 & 0.7 & 0.5 & 0.6 & 0.7 \\
\hline Z: Social problems & 0.2 & 0.5 & 0.5 & 0.5 & 0.6 & 0.8 & 0.7 & 0.7 & 0.5 & 0.7 & 0.7 \\
\hline Number of consultations with identified patients & $1,091,483$ & 106,655 & 50,499 & 38,967 & 33,114 & 28,192 & 25,471 & 23,223 & 21,162 & 19,172 & 17,474 \\
\hline
\end{tabular}

other studies $[3,4,9-11,17,18]$. Only $0.8 \%$ of the original cohort remained persistent FAs every year during the 10-year period. However, a higher percentage of the cohort patients were temporary FAs in some of the years, e.g. $6.2 \%$ in 2017.The average number of consultations per patient in the cohort remained high throughout the period, still more than twice the normal level in 2017. It may therefore be speculated that the FAs consist of two different groups of patients. One group has typically a temporary medical problem that

Table 4 Distribution (percentage of consultations) of the most common psychological diagnoses in 2008 and in a cohort of frequent attenders in 2008 in subsequent years

\begin{tabular}{|c|c|c|c|c|c|c|c|c|c|c|c|}
\hline \multirow[b]{2}{*}{ ICPC-2 codes } & \multirow[b]{2}{*}{$\begin{array}{l}\text { All } \\
2008\end{array}$} & \multicolumn{10}{|c|}{ Identified patients with five or more $\mathrm{OOH}$ consultations in 2008 (frequent attenders in 2008) } \\
\hline & & 2008 & 2009 & 2010 & 2011 & 2012 & 2013 & 2014 & 2015 & 2016 & 2017 \\
\hline P01: Feeling anxious, nervous, tense & 5.3 & 5.5 & 5.4 & 4.4 & 4.0 & 5.7 & 4.4 & 6.9 & 8.5 & 9.8 & 11.0 \\
\hline P02: Acute stress reaction & 7.1 & 4.3 & 3.1 & 3.8 & 3.6 & 5.0 & 4.2 & 2.7 & 3.1 & 2.9 & 3.3 \\
\hline P06: Sleep disturbance & 3.2 & 2.5 & 2.2 & 1.9 & 2.2 & 2.1 & 2.0 & 1.5 & 1.5 & 1.8 & 1.9 \\
\hline P15: Chronic alcohol abuse & 7.0 & 9.7 & 9.7 & 11.3 & 11.5 & 12.5 & 14.8 & 10.7 & 10.3 & 9.4 & 8.7 \\
\hline P16: Acute alcohol abuse & 8.9 & 6.2 & 6.7 & 6.2 & 5.3 & 9.0 & 7.4 & 7.2 & 7.6 & 7.5 & 7.5 \\
\hline P19: Drug abuse & 6.8 & 8.7 & 9.1 & 10.3 & 11.4 & 11.8 & 13.4 & 12.1 & 10.9 & 12.4 & 10.5 \\
\hline P72: Schizophrenia & 3.9 & 5.5 & 5.6 & 6.5 & 6.7 & 6.6 & 7.1 & 6.2 & 4.6 & 5.0 & 5.1 \\
\hline P74: Anxiety disorder. Anxiety state & 8.5 & 9.9 & 9.2 & 9.1 & 9.5 & 6.4 & 7.2 & 6.3 & 6.1 & 5.4 & 5.0 \\
\hline P76: Depressive disorder & 12.9 & 10.9 & 10.0 & 9.3 & 8.7 & 5.6 & 5.3 & 6.0 & 5.7 & 5.1 & 5.4 \\
\hline P77: Suicide. Suicide attempt & 3.5 & 3.6 & 3.6 & 4.0 & 3.7 & 4.0 & 4.2 & 5.4 & 6.0 & 7.4 & 6.8 \\
\hline P80: Personality disorder & 1.4 & 3.1 & 3.3 & 3.8 & 3.8 & 2.6 & 3.6 & 5.1 & 5.3 & 4.9 & 5.7 \\
\hline P98: Psychosis, other & 3.4 & 2.7 & 3.1 & 2.6 & 3.0 & 2.3 & 2.6 & 2.6 & 2.9 & 2.5 & 2.4 \\
\hline P99: Psychological disorder, other & 5.4 & 7.7 & 9.9 & 7.9 & 6.7 & 8.6 & 6.7 & 8.6 & 7.2 & 5.3 & 8.2 \\
\hline $\begin{array}{l}\text { Number of consultations with identified } \\
\text { patients }\end{array}$ & 47,189 & 13,771 & 7862 & 6570 & 5334 & 4868 & 4665 & 4059 & 3689 & 3213 & 2865 \\
\hline
\end{tabular}




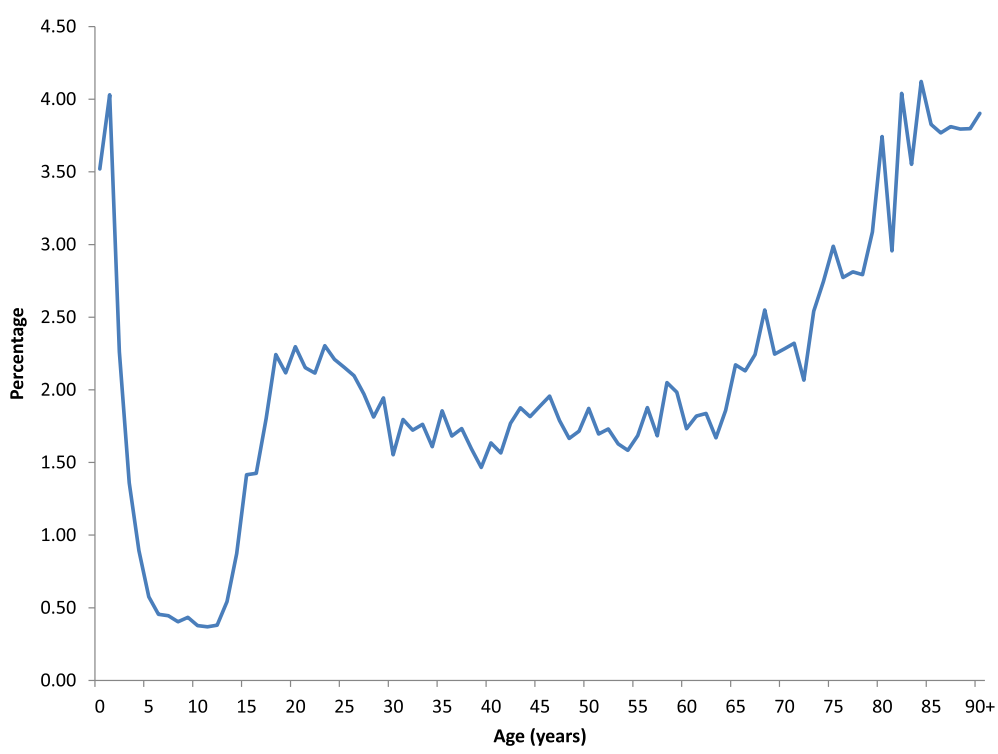

Fig. 1 Percentage of frequent attenders (of all OOH patients) according to age in 2017

requires several consultations during a relatively short period of time, while another group is prone to use $\mathrm{OHH}$ services for several reasons over a longer period of time, and thus develops habituation to $\mathrm{OOH}$ use for both urgent and non-urgent situations.

The age distribution in the cohort changed as expected over the years, with the exception of the youngest FAs (aged 0-1 years) who continued to consult frequently over the years, probably an effect of the parents' help seeking behaviour [28]. It remains to see if these children continue with frequent attendance when they grow old enough to decide for themselves.

Over time the remaining 2008 cohort consisted of more female patients, and an increasing percentage of the consultations were for psychological and social problems. Other studies of persistent FAs have drawn similar conclusions. In a study from Dutch general practice persistence was predicted by psychological, social and addictive disorder, and chronic somatic disease, but not by gender and age $[10,11]$. In an Australian community study persistence was associated with female gender, depression, disability and poor self-reported health [24]. A Swedish general practice study found that a large majority of persistent FAs were females [9]. A study of persistent FAs at a US university hospital emergency department found that persistent FAs had more psychiatric problems and substance abuse [17]. Similar findings have been reported from New Zealand [18].

Psychological problems are obviously a hallmark of frequent and persistent attendance $[4,6,7,12]$, but there

-All $\longrightarrow 2 \longrightarrow \geq 10 \longrightarrow 20$

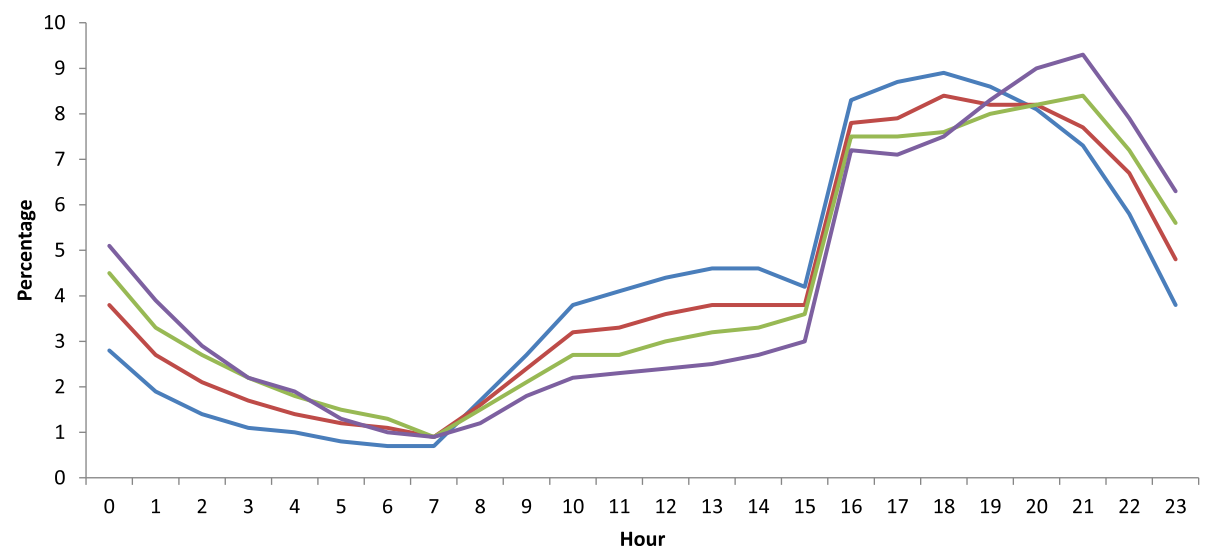

Fig. 2 Distribution of $\mathrm{OOH}$ consultations during day and night for all patients, and for frequent attenders with $\geq 5$ consultations, $\geq 10$ consultations or $\geq 20$ consultation in 2017 
Table 5 Diagnostic distribution (percentage of consultations) and characteristics of patients and consultations with different definitions of frequent attenders according to frequency of consultations (2017)

\begin{tabular}{|c|c|c|c|c|c|}
\hline ICPC-2 chapter & All & $\geq 5$ consultations & $\geq 10$ consultations & $\geq 20$ consultations & $\geq 30$ consultations \\
\hline A: General. unspecified & 13.3 & 14.7 & 14.9 & 15.0 & 16.7 \\
\hline B: Blood etc. & 0.3 & 0.4 & 0.5 & 0.7 & 0.9 \\
\hline D: Digestive & 10.6 & 11.9 & 11.6 & 12.2 & 12.3 \\
\hline F: Eye & 4.4 & 1.5 & 0.8 & 0.4 & 0.3 \\
\hline H: Ear & 2.5 & 1.7 & 0.8 & 0.3 & 0.1 \\
\hline K: Cardiovascular & 3.8 & 4.5 & 4.1 & 3.7 & 3.5 \\
\hline L: Musculoskeletal & 16.6 & 9.7 & 8.2 & 6.2 & 4.7 \\
\hline N: Neurological & 4.3 & 4.5 & 4.6 & 4.6 & 3.8 \\
\hline P: Psychological & 5.0 & 16.3 & 28.0 & 33.6 & 34.0 \\
\hline R: Respiratory & 18.5 & 17.5 & 11.4 & 7.4 & 7.5 \\
\hline S: Skin & 11.1 & 6.3 & 6.2 & 8.2 & 9.5 \\
\hline T: Endocrine etc. & 0.9 & 1.3 & 1.2 & 0.7 & 0.6 \\
\hline U: Urological & 5.8 & 6.6 & 4.7 & 3.2 & 2.1 \\
\hline W: Pregnancy etc. & 1.0 & 0.8 & 0.4 & 0.1 & 0.1 \\
\hline X: Female genital & 0.8 & 0.7 & 0.6 & 0.5 & 0.1 \\
\hline Y: Male genital & 0.7 & 0.6 & 0.6 & 0.9 & 1.2 \\
\hline Z: Social problems & 0.3 & 0.9 & 1.4 & 2.3 & 2.3 \\
\hline Number of consultations with identified patients & $1,373,987$ & 136,773 & 38,820 & 13,398 & 6785 \\
\hline Number of patients & 946,176 & 18,876 & 2462 & 429 & 150 \\
\hline Number of consultations per patient & 1.5 & 7.2 & 15.8 & 31.2 & 45.2 \\
\hline Percentage females & 51.6 & 54.8 & 56.3 & 63.4 & 63.3 \\
\hline Mean age & 37.7 & 42.4 & 45.4 & 43.1 & 41.5 \\
\hline Percentage home visits & 4.8 & 11.5 & 14.7 & 15.4 & 16.6 \\
\hline Percentage consultations during weekends & 40.7 & 37.8 & 36.8 & 35.5 & 34.8 \\
\hline Percentage consultations with time fee & 39.7 & 46.5 & 48.7 & 49.3 & 48.2 \\
\hline
\end{tabular}

are differences between single diagnoses. We found that some short term psychiatric problems are less common among FA, such as acute stress reaction, sleep disturbance or depressive disorder. On the other hand more chronic conditions such as schizophrenia, personality disorder, drug abuse and chronic alcohol abuse were clearly overrepresented among FAs and persistent FAs.

The characteristics of very frequent or extreme attenders ( $\geq 10, \geq 20$, and $\geq 30$ consultations) were similar to persistent FAs, with a larger percentage of females and more psychological and social problems than ordinary FAs. This is in line with other studies of very frequent or extreme FAs $[4,12,13]$. We also found that extreme FAs tended to seek help at inconvenient hours (late evening and night), and increasingly so the more extreme they were. Also, they needed more consultation time and more often received home visits. It is no surprise that these patients can be a challenge for the doctor on call.
The logistic regression analysis confirmed the findings in the descriptive analyses. In addition, we found that FAs were more common in small municipalities. It is known that overall $\mathrm{OOH}$ contact rates are higher in rural municipalities than in urban areas [29]. OOH services in smaller municipalities care for fewer patients and the doctor on call is less busy than in more populous municipalities. Furthermore, it is often the same doctor who manages the patient both during working hours and $\mathrm{OOH}$. $\mathrm{OOH}$ doctors in the smallest municipalities do home visits 4-6 times as frequently as doctors in larger municipalities (percentage of all contacts) [27]. It is quite possible that some of the $\mathrm{OOH}$ consultations in these municipalities are performed because they are simply more convenient for both patient and doctor than during working hours.

Chronic somatic illness have been found to predict frequent attendance in general practice $[10,11,20]$, as well as in $\mathrm{OOH}$ services $[6,10]$. We found that COPD and 
Table 6 Odds ratio for being a frequent attender $(n=18,876)$ at $\mathrm{OOH}$ services in 2017 ( $n=946,176$ patients)

\begin{tabular}{|c|c|c|c|}
\hline & $\mathrm{N}$ & Odds ratio & $\begin{array}{l}95 \% \text { confidence } \\
\text { interval }\end{array}$ \\
\hline \multicolumn{4}{|l|}{ Gender } \\
\hline Male (ref.) & 457,965 & & \\
\hline Female & 488,211 & 1.17 & $1.13-1.20$ \\
\hline \multicolumn{4}{|l|}{ Age groups } \\
\hline 16-69 (ref.) & 590,010 & & \\
\hline $0-1$ & 51,822 & 3.46 & $3.28-3.64$ \\
\hline $2-15$ & 167,658 & 0.71 & $0.67-0.75$ \\
\hline $70+$ & 136,686 & 1.57 & $1.51-1.64$ \\
\hline \multicolumn{4}{|l|}{ Number of inhabitants in municipality } \\
\hline$>50,000$ (ref.) & 337,545 & & \\
\hline $10,001-50,000$ & 454,610 & 0.96 & $0.93-0.99$ \\
\hline $5001-10,000$ & 83,370 & 1.23 & $1.17-1.30$ \\
\hline $2001-5000$ & 57,123 & 1.27 & $1.19-1.34$ \\
\hline$\leq 2000$ & 13,528 & 1.61 & $1.46-1.77$ \\
\hline $\begin{array}{l}\text { Psychological diagnosis } \\
\text { (ref. category: all other) }\end{array}$ & 46,988 & 10.00 & $9.66-10.36$ \\
\hline $\begin{array}{l}\text { Social diagnosis } \\
\text { (ref. category: all other) }\end{array}$ & 4025 & 5.97 & $5.45-6.53$ \\
\hline $\begin{array}{l}\text { Cancer diagnosis } \\
\text { (ref. category: all other) }\end{array}$ & 3811 & 6.76 & $6.09-7.51$ \\
\hline $\begin{array}{l}\text { Diabetes } \\
\text { (ref. category: all other) }\end{array}$ & 4383 & 4.65 & $4.18-5.18$ \\
\hline $\begin{array}{l}\text { Chronic obstructive pulmonary } \\
\text { disease } \\
\text { (ref. category: all other) }\end{array}$ & 7828 & 7.81 & $7.27-8.39$ \\
\hline
\end{tabular}

diabetes were more common among FAs than among ordinary attenders. Probably, complications and exacerbations of chronic conditions are the reasons for this help seeking behaviour.

A study from 2014 found that cancer patients received more home visits from the $\mathrm{OOH}$ services than non-cancer patients [30]. The same study concluded that there was no indication of overuse of $\mathrm{OOH}$ services by cancer patients in Norway. The present study leaves this conclusion in doubt. We found that there was almost a sevenfold chance for a cancer patient to become a FA compared with non-cancer patients. This finding indicates that there is a potential for improving the daily health care for cancer patients. It should be organized in such a way that there is less need for them to consult random $\mathrm{OOH}$ doctors.

More accessible health care services during office hours would probably reduce the pressure on $\mathrm{OOH}$ services. Half of all patients interviewed at an $\mathrm{OOH}$ service were willing to wait until the next day to see their personal physician, provided they were guaranteed an appointment [2]. It is quite obvious that not only cancer patients, but also patients with psychosocial problems are better served by a doctor who can provide a continuous relationship.

Future research should aim towards a better understanding of the help-seeking behaviour of FAs, especially those who consult repeatedly for non-urgent problems. Probably, qualitative methods would be a proper approach for this type of research. Interventions could be designed to reduce the need for consulting $\mathrm{OOH}$ services [5]. And for policy makers an important task would be to increase the capacity and accessibility of daytime general practice.

\section{Strengths and limitations}

There is no well-defined definition of FA. We chose to use $\geq 5$ consultations per year, while others have used both more or less. With our definition, $10 \%$ of all consultations were ascribed to FAs. We think this is a reasonable choice, and would argue against setting the threshold so low that almost half of all consultations are included. Furthermore, the size of the present material makes it possible to analyse even more extreme FAs with reasonable power.

Reimbursement claims are prepared for all contacts, and we may therefore assume that all $\mathrm{OOH}$ consultations have been registered. There is also reason to assume that the information on gender, age, municipality, time of inquiry and fee codes is correct.

Although formal criteria for the use of ICPC-2 diagnostic codes are available, it is not common to check these in daily clinical activities. This lack of diagnostic precision is likely to be evenly distributed through the material, and we believe that the differences between various groups and over time still remain valid, especially at ICPC-2 chapter level. The annual statistics also demonstrate stable diagnostic distribution for consultations from year to year [27].

In $200822.2 \%$ of the consultations had to be excluded because of lack of a pseudo-id. The diagnostic distribution among these differed slightly from those who were identified by pseudo-id. However, in 2017 only $1.7 \%$ of all consultations were unidentified.

Our data are probably representative for countries with similar health care systems, i.e. mainly tax financed, based on general practitioners, preferably organized in a list system, and with gate keeping for secondary care.

\section{Conclusion}

Frequent attenders were most common among the youngest children and among the elderly, increasing with age. Females were overrepresented, as were patients with psychosocial problems and various chronic somatic conditions. The majority were only temporary frequent 
attenders. Persistent, very frequent or extreme attenders were characterized by an even larger percentage of females and more psychological and social problems. Probably, increased accessibility at daytime general practice would reduce the need for frequent use of $\mathrm{OOH}$ services. For a group of frequent attenders with mainly non-urgent encounters, there may be a need of an individually focused intervention in collaboration with the patient's general practitioner and other primary care services in the municipality.

\section{Abbreviations}

COPD: Chronic obstructive pulmonary disease; FA: Frequent attender; HELFO: Norwegian Health Economics Administration; ICPC-2: International Classification of Primary Care 2 nd edition; $\mathrm{OOH}$ : Out of hours; RGP: Regular general practitioner; VFA: Very frequent attender

\section{Availability of data and materials}

The data that support the findings of this study are available from HELFO, but restrictions apply to the availability of these data, which were used under license for the National Centre for Emergency Primary Health Care. Data are however available from the authors upon reasonable request and with permission of HELFO.

\section{Authors' contributions}

HS designed the study, analysed the data, and drafted the manuscript. SH participated in the interpretation of the data, revising the manuscript, and approving the final version. Both authors have read and approved the final manuscript.

\section{Ethics approval and consent to participate}

The annual statistics were assessed by the data protection officer in the Norwegian Labour and Welfare Administration and the Data Protection Official for Research. Since no individuals can be identified either directly or indirectly in the material, the project was not subject to duty of notification pursuant to the Personal Data Act.

\section{Consent for publication}

Not applicable.

\section{Competing interests}

The authors declare that they have no competing interests.

\section{Publisher's Note}

Springer Nature remains neutral with regard to jurisdictional claims in published maps and institutional affiliations.

\section{Author details \\ ${ }^{1}$ National Centre for Emergency Primary Health Care, Uni Research Health, Kalfarveien 31, 5018 Bergen, Norway. ${ }^{2}$ Department of Global Public Health and Primary Care, University of Bergen, Kalfarveien 31, 5018 Bergen, Norway.}

Received: 7 May 2018 Accepted: 19 June 2018

Published online: 25 June 2018

\section{References}

1. Keizer E, Smits M, Peters Y, Huibers L, Giesen P, Wensing M. Contacts with out-of-hours primary care for nonurgent problems: patients'beliefs or deficiencies in healthcare? BMC Fam Pract. 2015;16:157.

2. Steen $\mathrm{K}$, Hunskaar $\mathrm{S}$. The new list patient system and emergency service in Bergen. Tidsskr Nor Laegeforen. 2004;124:365-6.

3. Vedsted P, Olesen F. Frequent attenders in out-of-hours general practice care: attendance prognosis. Fam Pract. 1999;16:283-8.

4. den Boer-Wolters D, Knol MJ, Smulders K, de Wit NJ. Frequent attendance of primary care out-of-hours services in the Netherlands: characteristics of patients and presented morbidity. Fam Pract. 2010;27:129-34.
5. Christensen MB, Christensen B, Mortensen JT, Olesen F. Intervention among frequent attenders of the out-of-hours service: a stratified cluster randomized controlled trial. Scand J Prim Health Care. 2004;22:180-6.

6. Buja A, Toffanin R, Rigon S, Lion C, Sandona P, Carraro D, et al. What determines frequent attendance at out-of-hours primary care services? Eur J Pub Health. 2015:25:563-8.

7. Vedsted $\mathrm{P}$, Christensen MB. Frequent attenders in general practice care: a literature review with special reference to methodological considerations. Public Health. 2005:119:118-37.

8. Vedsted P, Sorensen HT, Nielsen JN, Olesen F. The association between daytime attendance and out-of-hours frequent attendance among adult patients in general practice. Br J Gen Pract. 2001;51:121-4.

9. Andersson SO, Lynoe N, Hallgren CG, Nilsson M. Is frequent attendance a persistent characteristic of a patient? Repeat studies of attendance pattern at the family practitioner. Scand J Prim Health Care. 2004;22:91-4.

10. Smits FT, Brouwer HJ, ter Riet G, van Weert HC. Epidemiology of frequent attenders: a 3-year historic cohort study comparing attendance, morbidity and prescriptions of one-year and persistent frequent attenders. BMC Public Health. 2009;9:36.

11. Smits FT, Brouwer HJ, van Weert HC, Schene AH, ter Riet G. Predictability of persistent frequent attendance: a historic 3-year cohort study. Br J Gen Pract. 2009;59:e44-50.

12. Jelinek GA, Jiwa M, Gibson NP, Lynch AM. Frequent attenders at emergency departments: a linked-data population study of adult patients. Med J Aust. 2008:189:552-6.

13. Jacob R, Wong ML, Hayhurst C, Watson P, Morrison C. Designing services for frequent attenders to the emergency department: a characterisation of this population to inform service design. Clin Med (Lond). 2016;16:325-9.

14. Byrne M, Murphy AW, Plunkett PK, McGee HM, Murray A, Bury G. Frequent attenders to an emergency department: a study of primary health care use, medical profile, and psychosocial characteristics. Ann Emerg Med. 2003;41: 309-18

15. Street M, Berry D, Considine J. Frequent use of emergency departments by older people: a comparative cohort study of characteristics and outcomes. Int J Qual Health Care. 2018 [Epub ahead of print]; https://doi.org/10.1093/ intqhe/mzy062.

16. Dent A, Hunter G, Webster AP. The impact of frequent attenders on a UK emergency department. Eur J Emerg Med. 2010;17:332-6.

17. Kne T, Young R, Spillane L. Frequent ED users: patterns of use over time. Am J Emerg Med. 1998;16:648-52.

18. Kennedy D, Ardagh M. Frequent attenders at Christchurch Hospital's emergency department: a 4-year study of attendance patterns. N Z Med J. 2004;117:U871.

19. Vedsted P, Fink P, Olesen F, Munk-Jorgensen P. Psychological distress as a predictor of frequent attendance in family practice: a cohort study. Psychosomatics. 2001;42:416-22.

20. Jorgensen JT, Andersen JS, Tjonneland A, Andersen ZJ. Determinants of frequent attendance in Danish general practice: a cohort-based crosssectional study. BMC Fam Pract. 2016;17:9

21. Martin A, Martin C, Martin PB, Martin PA, Green G, Eldridge S. Inappropriate'attendance at an accident and emergency department by adults registered in local general practices: how is it related to their use of primary care? J Health Serv Res Policy. 2002;7:160-5.

22. Vedsted $\mathrm{P}$, Olesen F. Social environment and frequent attendance in Danish general practice. Br J Gen Pract. 2005;55:510-5.

23. Pasgaard AA, Maehlisen MH, Overgaard C, Ejlskov L, Torp-Pedersen C, Boggild $\mathrm{H}$. Social capital and frequent attenders in general practice: a register-based cohort study. BMC Public Health. 2018;18:310.

24. Pymont C, Butterworth P. Longitudinal cohort study describing persistent frequent attenders in Australian primary healthcare. BMJ Open. 2015;5:e008975.

25. Morken T, Myhr K, Raknes G, Hunskaar S. Organization of out-of-hours services in Norway [In Norwegian]. Report no. 4-2016. Bergen: National Centre for Emergency Primary Health Care, Uni Research Health; 2016. https://bora.uib.no/handle/1956/12957. Accessed 6 Jun 2018

26. WHO International Classification of Primary Care, Second edition (ICPC-2). http//www.who.int/classifications/icd/adaptations/icpc2/en/. Accessed 6 Jun 2018.

27. Sandvik H, Hunskaar S, Blinkenberg J. Statistics from out-of-hours primary health care 2017 [In Norwegian]. Report no. 2-2018. Bergen: National Centre for Emergency Primary Health Care, Uni Research Health; 2018. http://bora.uib.no/handle/1956/17544. Accessed 6 Jun 2018 
28. Lass M, Tatari CR, Merrild CH, Huibers L, Maindal HT. Contact to the out-ofhours service among Danish parents of small children - a qualitative interview study. Scand J Prim Health Care. 2018;36:216-23.

29. Sandvik H, Hunskaar S, Diaz E. Use of ermergency medical services by patients encompassed by the regular GP scheme. Tidsskr Nor Laegeforen. 2012;132:2272-6.

30. Thoresen CK, Sandvik H, Hunskaar S. Cancer patients'use of primary care out-of-hours services: a cross-sectional study in Norway. Scan J Prim Health Care. 2016;36:232-9.

Ready to submit your research? Choose BMC and benefit from:

- fast, convenient online submission

- thorough peer review by experienced researchers in your field

- rapid publication on acceptance

- support for research data, including large and complex data types

- gold Open Access which fosters wider collaboration and increased citations

- maximum visibility for your research: over $100 \mathrm{M}$ website views per year 